\title{
Research on Effect on Quality of Two-year-old Astragalus Membranaceus by Seed-Coating Treatment
}

\author{
X. B. LIU,W. C. REN, S. YAN, W. MA \\ College of Pharmacology, Heilongjiang University of TCM, China \\ L. MA \\ Northeast Forestry University, China
}

\begin{abstract}
The transformed situation of the content of astragaloside, flavonoids, saponins in two-year-old astragalus membranaceus (Fisch) Bge. has been studied through the treatment of astragalus seed-coating by different concentrations $(2 \%, 4 \%, 6 \%$ and $8 \%$ of seed dry weight) and the double controls of seed coated with ND general seed-coating ( $8 \%$ of seed dry weight) and seed uncoated. The study on one-year-old astragalus has indicated that the content of the main active component-astragaloside IV and total flavonoids in radix astragali has been increased after treated by astragalus seed-coating, and the residue of seed-coating can be fully degraded with the grow of plants. Based on the above study, this paper conducted the contrast research on the transformed situation of the active content in two-year-old astragalus, in order to further prove that the quality of astragalus can been improved through astragalus seed-coating.
\end{abstract}

KEYWORD: Astragalus membranaceus (Fisch) Bge; seed-coating; quality

\section{MATERIALS AND METHODS}

\subsection{Materials}

Astragalus species: astragalus membranaceus (Fisch) Bge., buying from the medical herbs company. Astragalus Seed-Coating Formulation (AM): provide by Heilongjiang August First Land Reclamation University, Chemical Control Research Department. ND Seed-Coating Formulation (ND): provide by Hei longjiang August First Land Reclamation University seed-coating Formulation Company. Rutin and Astragaloside Control Article were purchased from the National Institute for The Control of Pharmaceutical and Biological Products. $\mathrm{Me} \mathrm{OH}$ (chromatographic pure), 500ml. AN (chromatographic pure), 500ml. n-butanol (A.P), $500 \mathrm{ml}$. aethyl-acerbity ethyl ester(A.P), 500ml. aether (A.P), 500ml, provided by Tianjin Kermel Chemical Reagent Co., Ltd. High Performance Liquid phase waters 600 UV detector waters2487 manufactured by the U.S. Waters company; Spectrum 756 PC UV-Vis spectrophotometer.

\subsection{Methods}

\subsubsection{The basic conditions of the testing land}

Test was carried out on the soybean test base in Heilongjiang August First Land Reclamation University (east longitude $125^{\circ} 9^{\prime}$, northern latitude $\left.46^{\circ} 58^{\prime}\right)$, the ground expanse, crop- producing power uniformity, alkaline hydrolysis azotei : $178.50(\mathrm{mg} / \mathrm{kg})$, immediate effedt phos.: $25.40(\mathrm{mg} / \mathrm{kg})$, immediate effedt kalium: 257.40 $(\mathrm{mg} / \mathrm{kg})$, organic matter content is $3.08 \%$.

\subsubsection{The experiment design}

The test was run on May, 20th, 2006.The concrete coating method is : firstly the choice Astragalus seeds are heterotherm disposed for $12 \mathrm{~h}\left(41^{\circ} \mathrm{C}\right.$ constant temperature soak $4 \mathrm{~h}$, then $25^{\circ} \mathrm{C}$ keep moist closed the seeds $8 \mathrm{~h}$, usually change the water ), and use the absorbent paper to suction the surface water, Air-dry at room temperature for $30 \mathrm{~min}$, then coated through the treatment of astragalus seed-coating by different concentrations $(2 \%, 4 \%, 6 \%$ and $8 \%$ of seed dry weight) and the double controls of seed coated with ND general seed-coating ( $8 \%$ of seed dry weight) and seed uncoated as double controls. then sowing. distance between rows: $45 \mathrm{~cm}$, distance between hills: $10 \mathrm{~cm}$, areola areas $8 \mathrm{~m} 2$, randomized blocks arrange, administered as farmland.

\subsection{Sampling and Testing Methods}

On half of May in the second year after planting, sampling for astragaloside-IV, the total saponins and flavonoids content. Meantime on Mid July sampling for measure the biological yield in unit area, select the typical 8 plants for measure the underground, the ground part growth level. The measured data of 
mean value as the processing astragalus group character value. The test was three times repeated.

\subsubsection{Assay method of Astragaloside- IV}

Testing instruments, processing conditions as follows:

Chromatographic condition:

Chromatographic column: C18, $250 \times 4.6 \mathrm{~mm}, 5 \mu$.

Tcol: $30.0^{\circ} \mathrm{C}$. DET $(\lambda): 202 \mathrm{~nm}$. F: $0.8 \mathrm{~mL} / \mathrm{min}$. RNAGE: 0.05AUFS. Vinj: 20M1.

Moving phase: ACN: water $=32: 68$.

Standard preparation concentration: $750 \mathrm{mg} / \mathrm{L}$.

Processing conditions: Take the Astragalus root powder $4 \mathrm{~g}$, put into the Soxhlet apparatus, add $\mathrm{Me}$ $\mathrm{OH} 40 \mathrm{ml}$, cold dipped over the night. then add $\mathrm{Me}$ $\mathrm{OH} 40 \mathrm{ml}$,heat $80^{\circ} \mathrm{C}$ and backstreaming $4 \mathrm{~h}$, the extraction Concentrated to dry. add n-butanol saturated water $20 \mathrm{ml}$ with ultrasound appearance to dissolve, water saturated $\mathrm{N}$-butanol extract 4th, every time $40 \mathrm{ml}$, merger N-butanol. With $1 \% \mathrm{Na}$ $\mathrm{OH}$ washing 3 times, every time $40 \mathrm{ml}$, abandon the $\mathrm{Na} \mathrm{OH}$ layer. with $\mathrm{N}$-butanol saturated water wash to neutral. N-butanol layer evaporate to dry, add water 5ml, through $\mathrm{C} 18$ solid phase column extractor, first wash with water $3 \mathrm{ml}$, then wash with $20 \% \mathrm{Me} \mathrm{OH} 5 \mathrm{ml}$, abandon the eluant. Finally, wash with $60 \% \mathrm{Me} \mathrm{OH} 20 \mathrm{ml}$ collect the eluant, evaporat to dry. $\mathrm{Me} \mathrm{OH}$ volume to $5 \mathrm{ml}$, prepared for testing.

\subsubsection{Assay methods of total flavonoids and saponins}

Determination wavelength of total flavonoids: $510 \mathrm{~nm}$. Determination wavelength of total saponin: 598nm.

Take Astragalus roots and leaves powder each $2 \mathrm{~g}$, put into the Soxhlet apparatus separately, Plus $40 \mathrm{ml}$ aether to skim until colorless, the filter paper tube evaporate aether to dry, add $\mathrm{Me} \mathrm{OH} 40 \mathrm{ml}$, heat $90{ }^{\circ} \mathrm{C}$ backstreaming extract $2 \mathrm{~h}$, every time $2.5 \mathrm{~h}$. extraction Concentrated to dry, put water $20 \mathrm{ml}$ into the Residues then heat to solute, sucking filtration, take the water bath phase using water saturation aethyl-acerbity ethyl ester to extract 4 times, every time $20 \mathrm{ml}$, the extraction reclaimed solvent. Residues plus methanol metered volume in the volume of $25 \mathrm{ml}$ measuring flask, get total flavonoids, to test; mother liquid plus water saturation $\mathrm{N}$-butanol to extract 4 times, every time $20 \mathrm{ml}$, the extraction reclaimed solvent, Residues plus methanol metered volume in the volume of $25 \mathrm{ml}$ measuring flask, get total saponin to test.

\section{THE RESULTS AND ANALYSIS}

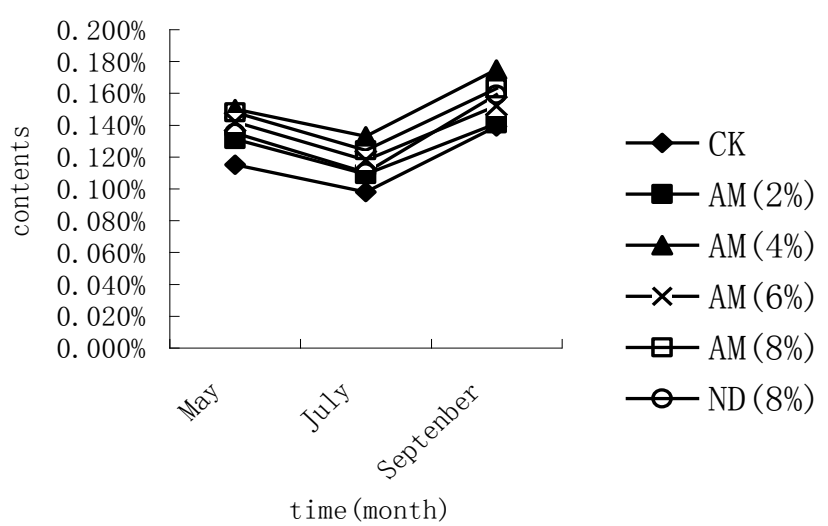

Figure1 Treatment on contents of astragalosid IV

Chart 1 Treatment on contents of total flavonoid

\begin{tabular}{|c|c|c|c|c|c|c|}
\hline & \multicolumn{2}{|c|}{ May } & \multicolumn{2}{|c|}{ July } & \multicolumn{2}{|c|}{ September } \\
\hline & leave & root & leave & root & leave & root \\
\hline CK & $0.387 b$ & $0.257 \mathrm{c}$ & $0.469 \mathrm{c}$ & $0.240 \mathrm{~b}$ & $0.518 \mathrm{~d}$ & $0.292 b$ \\
\hline $\operatorname{AM}(2 \%)$ & $0.357 \mathrm{c}$ & $0.245 d$ & $0.475 b c$ & $0.246 b$ & $0.515 \mathrm{~d}$ & $0.287 b$ \\
\hline $\operatorname{AM}(4 \%)$ & $0.417 \mathrm{a}$ & $0.293 a$ & $0.496 a$ & $0.270 \mathrm{a}$ & $0.595 \mathrm{a}$ & $0.310 \mathrm{a}$ \\
\hline $\operatorname{AM}(6 \%)$ & $0.393 b$ & $0.282 b$ & $0.471 b c$ & $0.247 b$ & $0.549 \mathrm{bc}$ & $0.301 \mathrm{ab}$ \\
\hline $\operatorname{AM}(8 \%)$ & $0.410 \mathrm{a}$ & $0.273 b$ & $0.479 b$ & $0.264 a$ & $0.554 b$ & $0.305 \mathrm{ab}$ \\
\hline $\mathrm{ND}(8 \%)$ & $0.392 b$ & $0.277 \mathrm{~b}$ & $0.464 \mathrm{c}$ & $0.259 \mathrm{a}$ & $0.536 \mathrm{c}$ & $0.297 b$ \\
\hline
\end{tabular}

* Letters a, b, c said that dealing with poor test new rehabilitation difference was significant, $n=3$ 
Chart2 Treatment on contents of total saponin

\begin{tabular}{|c|c|c|c|c|c|c|}
\hline & \multicolumn{2}{|c|}{ May } & \multicolumn{2}{|c|}{ July } & \multicolumn{2}{|c|}{ September } \\
\hline & leave & root & leave & root & leave & root \\
\hline $\mathrm{CK}$ & $2.061 b c$ & $1.134 \mathrm{e}$ & $1.820 \mathrm{f}$ & $0.714 \mathrm{f}$ & $2.151 \mathrm{c}$ & $0.887 \mathrm{~d}$ \\
\hline $\operatorname{AM}(2 \%)$ & $2.034 \mathrm{c}$ & $1.091 \mathrm{f}$ & $1.834 \mathrm{e}$ & $0.763 d$ & $2.157 \mathrm{c}$ & $0.892 \mathrm{~d}$ \\
\hline $\operatorname{AM}(4 \%)$ & $2.211 \mathrm{a}$ & $1.206 \mathrm{a}$ & $1.944 b$ & $1.040 \mathrm{a}$ & $2.171 \mathrm{ab}$ & $0.964 \mathrm{a}$ \\
\hline $\operatorname{AM}(6 \%)$ & $2.090 \mathrm{~b}$ & $1.159 \mathrm{c}$ & $1.991 \mathrm{a}$ & $0.903 b$ & $2.166 \mathrm{~b}$ & $0.912 c$ \\
\hline $\operatorname{AM}(8 \%)$ & $2.162 \mathrm{ab}$ & $1.177 \mathrm{~b}$ & $1.933 \mathrm{c}$ & $0.865 \mathrm{c}$ & $2.178 \mathrm{a}$ & $0.943 b$ \\
\hline $\mathrm{ND}(8 \%)$ & $2.112 \mathrm{~b}$ & $1.143 \mathrm{~d}$ & $1.865 \mathrm{~d}$ & $0.741 \mathrm{e}$ & $2.162 b c$ & $0.925 c$ \\
\hline
\end{tabular}

* Letters a, b, c said that dealing with poor test new rehabilitation difference was significant, $n=3$

\subsection{The seed-coating effect on the astragalosid IV of agstragalas born in two years}

Figure 1 indicates that the content of astragalosid IV can be increased after treated by Astragalus seedcoating Formulation. From each month of the second year after sowing to see, Astragaloside IV content along with the increase of Astragalus seedcoating concentration presents a dynamic changes first increase then decline, the maximum increase group is AM (4\%), compared with CK increase by $0.035 \%, 0.035 \%$ and $0.036 \%$, the other coating groups have different degree raise than CK group; While compared to ND seed-coating of the same concentration, Astragaloside IV content which is processed by ND seed-coating to be lower than the Astragalus one, in each month after sowing is low by $0.013 \%, 0.014 \%$ and $0.004 \%$. The above interclass empirical study has indicated that, AM (4\%)treatment is the most suitable coating concentration. At the same time, Astragalus seedcoating because of its low toxicity and high-quality is better than ND seed-coating which is commonly used in the field to enhance the quality of Astragalus. Within the same group experimental research shows that: Astragaloside IV content in the germinating period in May and dormancy period in September has visibly raised to the growing period in July, which indicates that Astragalus is appropriate for spring and autumn to harvest.

\subsection{The seed-coating effect on the total flavonoids and saponins of agstragalas born in two years}

Treatment on content of total flavonoid as chart 1 , we can see that, using astragalus seed-coating treated can improve the content of total flavonoid, AM (4\%) treatment group is the max , next are AM $(8 \%)$ and AM $(6 \%)$ treatment. From each month after sowing to see , AM (4\%) compared with $\mathrm{CK}$ increased by $0.036 \%, 0.030 \%$ and $0.018 \%$; while compared to ND seed-coating of the same concentration , Astragaloside IV content which is processed by ND seed-coating to be lower than the Astragalus one, in July and September after sowing are low by $0.005 \%$ and $0.008 \%$.

The total flavonoids content of leaves also taking AM (4\%) as the highest group, and over the same period which is in the roots ,show that the leaves have some use value.

Treatment on content of total saponin as chart 2, we can see that, using Astragalus seed-coating treated can improve the content of total saponin, as well as the same period the content of total saponin in the leaves obviously over which is in the roots. The two both at the highest of AM (4\%) treatment. In each month after sowing, the content of AM (4\%) treatment in the roots compared with $\mathrm{CK}$ is increased by $0.072 \%, 0.326 \%$ and $0.077 \%$. the content of AM (4\%) treatment in the leaves compared with CK increased by $0.15 \%, 0.124 \%$ and $0.02 \%$; While compared with ND seed-coating of the same concentration, the total saponin content which is processed by ND seed-coating to be lower than the Astragalus one, in the roots each low by $0.034 \%, 0.124 \%$ and $0.018 \%$, in the leaves each low by $0.05 \%, 0.068 \%$ and $0.016 \%$.

\section{CONCLUSION AND DISCUSSION}

As the perennial legume herbaceous plant, astragalus root is one of the commonly used benefiting Chinese medicine in our motherland [1]. Pieces of astragalus are widely used in clinical prescriptions, which have many pharmacological effects. such as activating heart, anti-myocardial ischemia, improving immunity, reduce blood sugar, anti-aging, the protection of organs and so on [2-3].Seedling diseases of astragalus will directly affect the quality of medicines. The use of seed-coating formulation can increase seed germination rate and promote the healthy growth of seedlings. Thus the development of high efficiency and low toxicity of astragalus seed-coating formulation will play an important role in improving the quality of the medicine. 
Astragalosides IV and total Saponin are the characteristic ingredient in traditional Chinese medicine. Astragaloside IV was included under the identification of astragalus item in Pharmacopoeia of Chinese. State the qualitative and quantitative determination of standards [4]. Japanese also makes it as a quantitative target for the evaluation of astragalus quality [5]. At present, astragalus medicinal herbs and the single and compound chinese drug preparations usually use the content of astragaloside IV and total saponin as the agents to evaluate the quality of traditional Chinese medicine [6]. In recent years, Zhang Guijuan et al. studies have shown that the total flavonoid in astragalus also has a wide range of pharmacological activities [7] .

In this experiment, studies have shown that appropriate concentration of Astragalus seed-coating can increase the content of astragaloside IV, total flavonoid and total saponin. At the same time, on the content of active ingredient, in the same concentration, the treatment of Astragalus seedcoating is more effective than ND seed-coating which is commonly used in field crops .

In recent years, study has found that Astragalus stems and leaves contain the same Astragalosi IV, flavonoids and polysaccharides ingredients, which indicates that the stems and leaves as roots also have some important medicinal value $[8,9]$.

The correlation studies have shown that dealing with the appropriate concentration of Astragalus seed-coating can increase the stem weight, and raise the total biological production, which is combined with experiments of this study showing that Astragalus seed-coating can significantly improve the quality of such medicinal herbs.

With the people all over the world more and more favoring the viridis Chinese medicine, the issue of pesticide residue in the drug gradually catches more and more peoples' attention [10]. The study on the one-year-old samples that are treated by Astragalus seed-coating have showed that the pesticide residue can be totally degraded in 150 days after the sowing.

By multiple comparison, we considered that between $4 \%$ and $\mathrm{CK}$ the difference was significant,so $4 \%$ was the best coating concentration .

Our test also shows that Astragalus IV content in the germinating period in May and dormancy period in September are higher than other periods, which indicates that Astragalus is appropriate for spring and autumn to harvest, which is coincide with the traditional harvest way.

\section{ACKNOWLEDGEMENTS}

This work was supported by grants from the Key Program of Natural Science Foundation of State (Grant No. 81274010), Heilongjiang province outstanding youth fund (Grant No. JC201101), and Talent fund of Heilongiiang University of Chinese Medicine Talent Fund.

\section{COMPETING FINANCIAL INTERESTS}

The authors declare no competing financial interests.

\section{REFERENCES}

[1] Wang Ping-Juan. Research on astragalus us biological characteristics and quality of different fields and different types in Jilin Province. Jilin Agricultural University master's thesis. 2006, 5.

[2] Zhang Yu-Ting. Modern pharmacological effects of astragalus and analysis of the blood disease. Practical Traditonal Chinese Internal Medicine, 2007, 21(2): 14-15.

[3] Jiang Jun-Yan, Chen Xu-Dong, Li Chang-Kun. The use and extraction of astragalan polysaccharide. Chemical Engineer, 2003, 97 (4): 55-56 (in Chinese).

[4] Pharmacopoeia of the People's Republic of China committee. Pharmacopoeia of the People's Republic of China. Chemical Industry Press, 2005 (1): 212.

[5] Jia Gui-Zhi, Yan Jing, Zhang Ning, et al. Compare of the components of different harvest time in cultivatal Astragalus. Chinese Medicine, 1996, 21(8): 381-383.

[6] Han Xiang-Peng, Luo De-Gong, Huang Xian-Fen, et al. Correlation analysis of the Mongolia astragaloside yield factor. Chinese Medicine, 2001, 24 (11): 782-785.

[7] Zhang Gui-Juan, Jiang Wei-Xin, Chen Ming-Xiao. Research on the active ingredient content of Astragalus leaves. Heilongjiang Medicine Journal, 2004, 17 (3): 163165.

[8] JOHN R1 J, BONNIE L R, SYED F A.3 - Dopamine toxicity following long term exposure to low doses of 3nitropropionic acid (3-NPA) in rats. Toxicology Letters1 2000, $116(1-2)$ : 113-1181.

[9] Jiang Wei-Xin, Yu Xiang-Yu, Shi Shen-Hua, et al. Research on the active ingredients extract Method in stem of astragalus. Journal of Harbin University of Commerce (Natural Sciences Edition), 2004, 20 (3): 272-274.

[10]Zhou Chang-Zhen, Wang Qing. Research and Prospect on Pesticide residue in Chinese medicine. Research \& Information On Traditional Chinese Medicine, 2002, 2 (2): 36. 